\title{
Mucinous Cystadenoma Causing Abdominal Distension: A Case Report
}

\author{
Alexandra M. Craen ${ }^{1}$, David Lebowitz ${ }^{2}$, Kendra Amico ${ }^{2}$, Latha Ganti ${ }^{2}$ \\ 1. Emergency Medicine, Ocala Regional Medical Center / University of Central Florida College of Medicine, Orlando, \\ USA 2. Emergency Medicine, University of Central Florida College of Medicine, Orlando, USA
}

Corresponding author: Alexandra M. Craen, alexcraen@gmail.com

\begin{abstract}
Mucinous cystadenomas are a common benign neoplasm of the ovaries that can grow much larger than other adnexal masses. We report a case of a 28 -year-old female who presented with one month of increasing abdominal distension and upper abdominal pain; she was found to have a 30-centimeter (cm) adnexal mass. Pathology showed a benign mucinous cystadenoma with no evidence of malignancy. The authors discuss the initial evaluation and management of adnexal masses in general, as the variety of etiologies and severity can make this a difficult task. The characteristics of different adnexal masses and the indications for gynecologic consultation and surgery are also discussed.
\end{abstract}

Received 10/08/2018 Review began 10/22/2018 Review ended 11/05/2018 Published 11/30/2018

(c) Copyright 2018 Craen et al. This is an open access article distributed under the terms of the Creative Commons Attribution License CC-BY 3.0., which permits unrestricted use, distribution, and reproduction in any medium, provided the original author and source are credited.
Categories: Emergency Medicine, Obstetrics/Gynecology, Oncology

Keywords: mucinous cystadenoma, ovarian mass, adnexal mass, benign neoplasm, abdominal distension, gynecological surgery, emergency medicine, cystic mass, abdominal pain, gynecologic cancer

\section{Introduction}

Adnexal masses can occur at any age of life and there is a wide variety of pathology, both gynecologic and nongynecologic. Imaging, lab markers, and possible surgical intervention with a pathologic study are necessary to properly diagnose these masses. Age and reproductive status can also help narrow down likely causes [1]. The risk for ovarian cancer increases after menopause: $70 \%$ of patients are 55 years and older. Women of reproductive age are more likely to have benign masses [2]. Mucinous cystadenomas are a common benign neoplasm of the ovaries and can become much larger compared to the more common serous cystadenomas [3-4]. Surgical intervention of adnexal masses is warranted if concern for malignancy exists or if the patient is symptomatic $[1,5]$.

\section{Case Presentation}

A 28-year-old, previously healthy woman presented to the emergency department (ED) with two months of abdominal distension and one week of upper abdominal pain. The distension had initially abated after two weeks, but then gradually worsened until presentation. Her upper abdominal pain worsened with movement and improved with sitting upright. She denied any nausea, vomiting, constipation, diarrhea, urinary symptoms, vaginal bleeding or discharge, or other complaints. She denied any prior history of abdominal distension or liver disease. She reported regular menstruation, and her last menstrual period was one week prior. Her past obstetric history was gravida three, para two, abortus one. She reported a family history of ovarian cancer and colon cancer in distant relatives.

Physical examination revealed a firmly distended abdomen with no fluid wave (Figure $)$. There was no focal tenderness, rebound, or guarding of the abdomen. There were no skin changes or extremity edema noted. Cardiovascular and pulmonary exams were unremarkable. 


\section{Cureus}

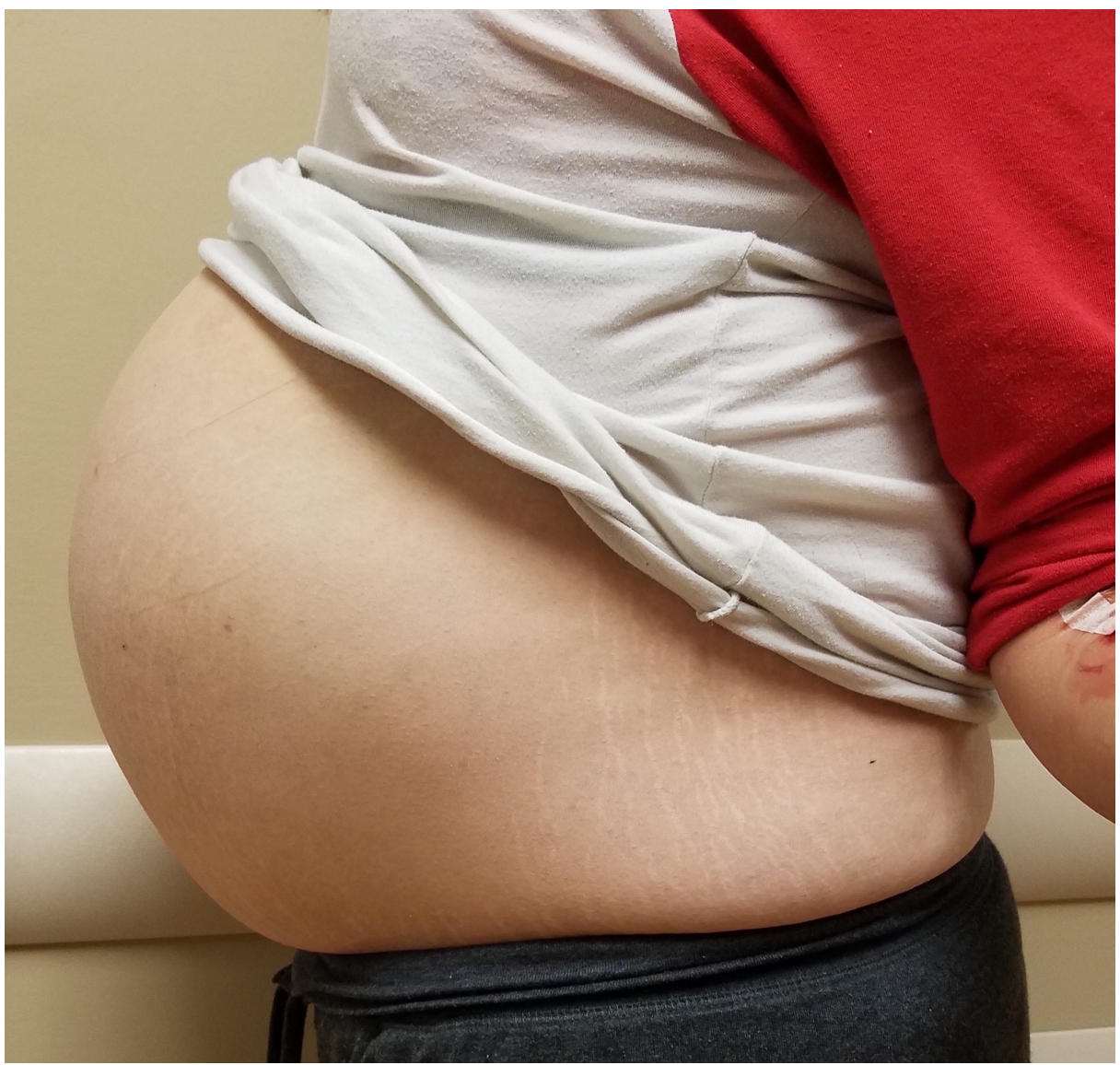

FIGURE 1: Abdominal distention of the patient.

A point of care transabdominal ultrasound at the bedside showed several, large cystic structures and no obvious pregnancy. Laboratory studies were unremarkable and her beta-hcg returned negative. A comprehensive abdominal ultrasound showed a large cystic mass arising from the chest to the pelvic area (Figure 2). As the source of the mass was unclear, a computed tomography (CT) scan of the abdomen and pelvis was performed and showed a multi-septated cystic mass, measuring 30.0 × $28.9 \times 19.0 \mathrm{~cm}$, arising from one of the adnexal regions (Figure 3). Gynecology was consulted and performed a laparotomy with left salpingo-oophorectomy the following day. A $30 \mathrm{~cm}$ adnexal mass was removed. Surgical pathology revealed a mucinous cystadenoma with no cytologic malignancy found. The patient made a full recovery.

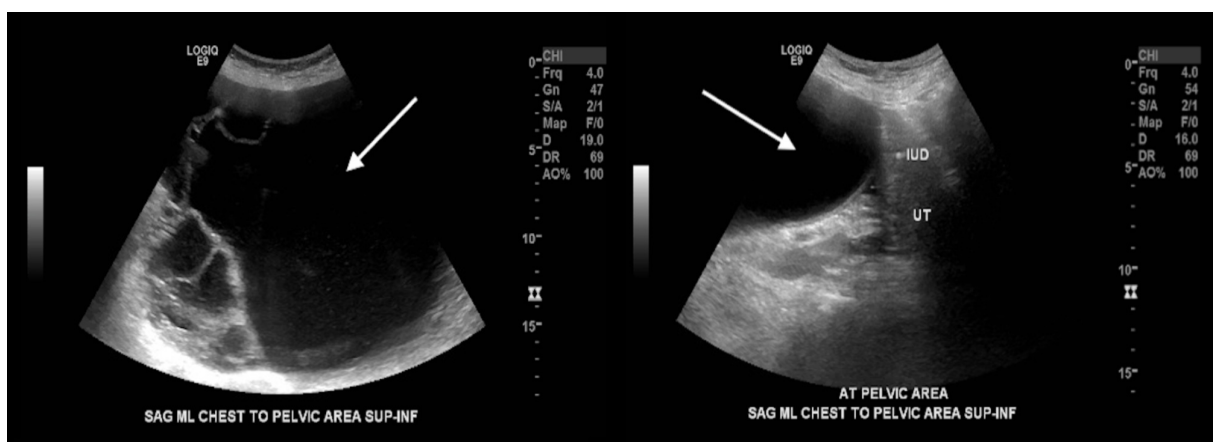

FIGURE 2: Transabdominal ultrasonography with two sagittal views of the upper abdomen and pelvic area showing a large cystic mass. 


\section{Cureus}

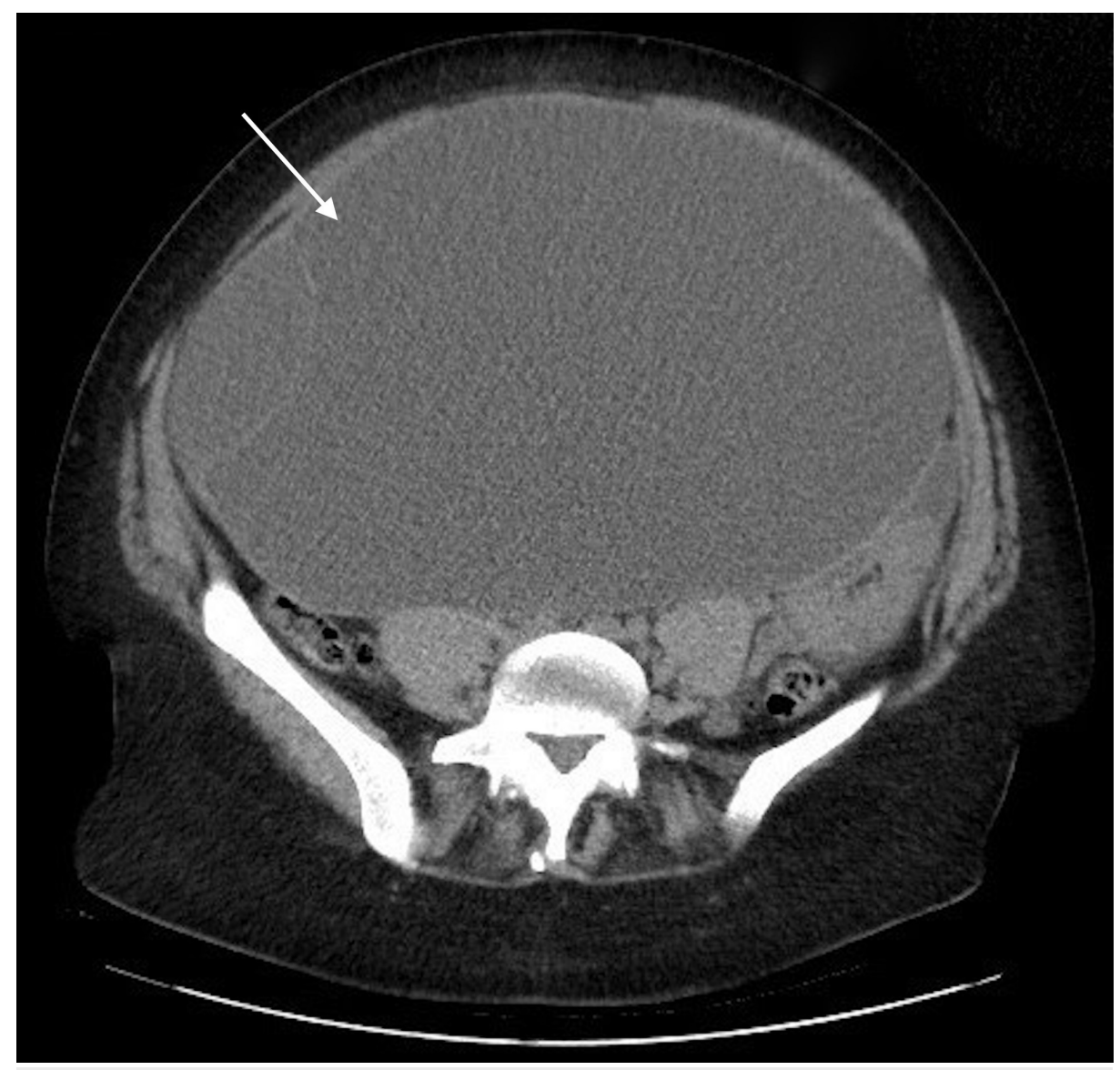

FIGURE 3: Axial computed tomography image of the abdomen at the level of the iliac crest showing a large cystic mass measuring up to $\mathbf{3 0}$

cm.

\section{Discussion}

Adnexal masses can be difficult to evaluate and manage because of the large differential diagnosis and variable urgency associated with differing etiologies. In the emergency department, a relevant history should also include risk factors for cancer. A family history of ovarian or breast cancer is a strong risk factor for a patient developing ovarian cancer with an increase from $1.6 \%$ to about $5 \%$ with one relative [6]. Other oncologic risk factors include nulliparity, infertility, early menstruation or late menopause, white race, and endometriosis $[1,6]$. A full physical examination is also warranted in any patient with abdominal pain or concern for malignancy. While the pelvic examination has not been shown to identify adnexal masses well, it is still recommended to assess for other etiologies [7]. It is important to consider emergent diagnoses, such as ectopic pregnancy, tubo-ovarian abscess, and adnexal mass with associated ovarian torsion [1].

Transvaginal ultrasonography is the recommended and most commonly used imaging modality to evaluate an adnexal mass [1]. Malignant characteristics on ultrasound include a size greater than $10 \mathrm{~cm}$, irregularity, papillary or solid structures, ascites, and high color Doppler flow on ultrasound. Benign characteristics include simple, thin-walled structures with no solid components or internal blood flow on Doppler ultrasound [8-9]. Masses believed to be benign, which are asymptomatic, may be observed with repeated transvaginal ultrasound rather than surgery $[1,5]$.

A CT scan was done in our ED after ultrasonography to better assess the source and size of the mass. CT scans can be helpful in detecting lymph node enlargement, metastases, ascites, and possible alternative primary sites of tumors [10]. The CT returned, showing a $30 \mathrm{~cm}$ multi-septated cystic mass arising from one of the adnexa. Some experts consider cysts greater than $10 \mathrm{~cm}$ an indication for surgery [1,11]. Our patient's mass was more than double this, prompting the gynecology team to take the patient to surgery the next day.

The pathology results showed a mucinous cystadenoma, which is a common benign adnexal neoplasm. They are larger and more likely to be multiloculated compared to serous cystadenomas, the most common benign neoplasm [4]. Other common benign adnexal masses in adult females include dermoid cysts and Brenner tumors [3]. Although benign, symptomatic patients experiencing pelvic pain, urinary symptoms, or 


\section{Conclusions}

Adnexal masses have a large variety of etiologies that can be difficult to diagnose on initial presentation. Mucinous cystadenomas are a type of benign adnexal neoplasm that can grow much larger than other masses. This caused the abdominal distension and pain seen in the patient discussed. The management of benign masses depends on the concern for malignancy, size, and patient's symptoms. Point of care or bedside ultrasound can guide in medical decision-making or diagnostics, many times enhancing our process by helping us decide which is the best next test or step in care.

\section{Additional Information}

\section{Disclosures}

Human subjects: Consent was obtained by all participants in this study. Conflicts of interest: In compliance with the ICMJE uniform disclosure form, all authors declare the following: Payment/services info: All authors have declared that no financial support was received from any organization for the submitted work. Financial relationships: All authors have declared that they have no financial relationships at present or within the previous three years with any organizations that might have an interest in the submitted work. Other relationships: All authors have declared that there are no other relationships or activities that could appear to have influenced the submitted work.

\section{References}

1. Eskander R, Berman M, Keder L: Practice bulletin no. 174: evaluation and management of adnexal masses . Obstet Gynecol. 2016, 128:1193-1195. 10.1097/AOG.0000000000001768

2. SEER cancer statistics review, 1975-2013. (2016). Accessed: September 10, 2018: https://seer.cancer.gov/archive/csr/1975_2013/.

3. Kurman RJ, Ellenson LH, Ronnett B: Blaustein's Pathology of the Female Genital Tract. Springer Science+Business Media, NY, US; 2011. 10.1007/978-1-4614-3165-7

4. Sayasneh A, Ekechi C, Ferrara L, et al.: The characteristic ultrasound features of specific types of ovarian pathology (review). Int J Oncol. 2014, 46:445-458. 10.3892/ijo.2014.2764

5. Froyman W, Landolfo C, Cock BD, et al.: OC01.01: Risk of complications in conservatively managed adnexal masses initially thought to be benign at subjective impression by the ultrasound examiner. Ultrasound Obstet Gynecol. 2017, 50:1. 10.1002/uog.17570

6. Kerlikowske K, Brown JS, Grady DG: Should women with familial ovarian cancer undergo prophylactic oophorectomy?. Obstet Gynecol. 1992, 81:700-707. 10.1016/0020-7292(93)90733-D

7. Padilla LA, Radosevich DM, Milad MP: Limitations of the pelvic examination for evaluation of the female pelvic organs. Int J Gynaecol Obstet. 2005, 88:84-88. 10.1016/j.ijgo.2004.09.015

8. Sokalska A, Timmerman D, Testa AC, et al.: Diagnostic accuracy of transvaginal ultrasound examination for assigning a specific diagnosis to adnexal masses. Ultrasound Obstet Gynecol. 2009, 34:462-470. 10.1002/uog.6444

9. Timmerman D, Testa AC, Bourne T, et al.: Simple ultrasound-based rules for the diagnosis of ovarian cancer. Ultrasound Obstet Gynecol. 2008, 31:681-690. 10.1002/uog.5365

10. Micco M, Sala E, Lakhman Y, Hricak H, Vargas HA: Role of imaging in the pretreatment evaluation of common gynecological cancers. Women's Health (Lond). 2014, 10:299-321. 10.2217/whe.14.19

11. Brun JL, Fritel X, Aubard Y, et al.: Management of presumed benign ovarian tumors: updated French guidelines. Eur J Obstet Gynecol Reprod Biol. 2014, 183:52-58. 10.1016/j.ejogrb.2014.10.012 